\title{
Early bent knee prostheses: ancestors of K9
}

\author{
D D'A WEBLING, M FAHRER
}

The area around the tibial tuberosity and patellar tendon is the best natural weightbearing part of the leg if the sole of the foot is injured or absent. The recently described orthopaedic scooter K9 exploits this weightbearing characteristic ${ }^{1}$ but is not an entirely novel device. We have noticed that bent knee prostheses are depicted in paintings dating from the fifteenth and sixteenth centuries, and a cripple depicted on a vase made in the

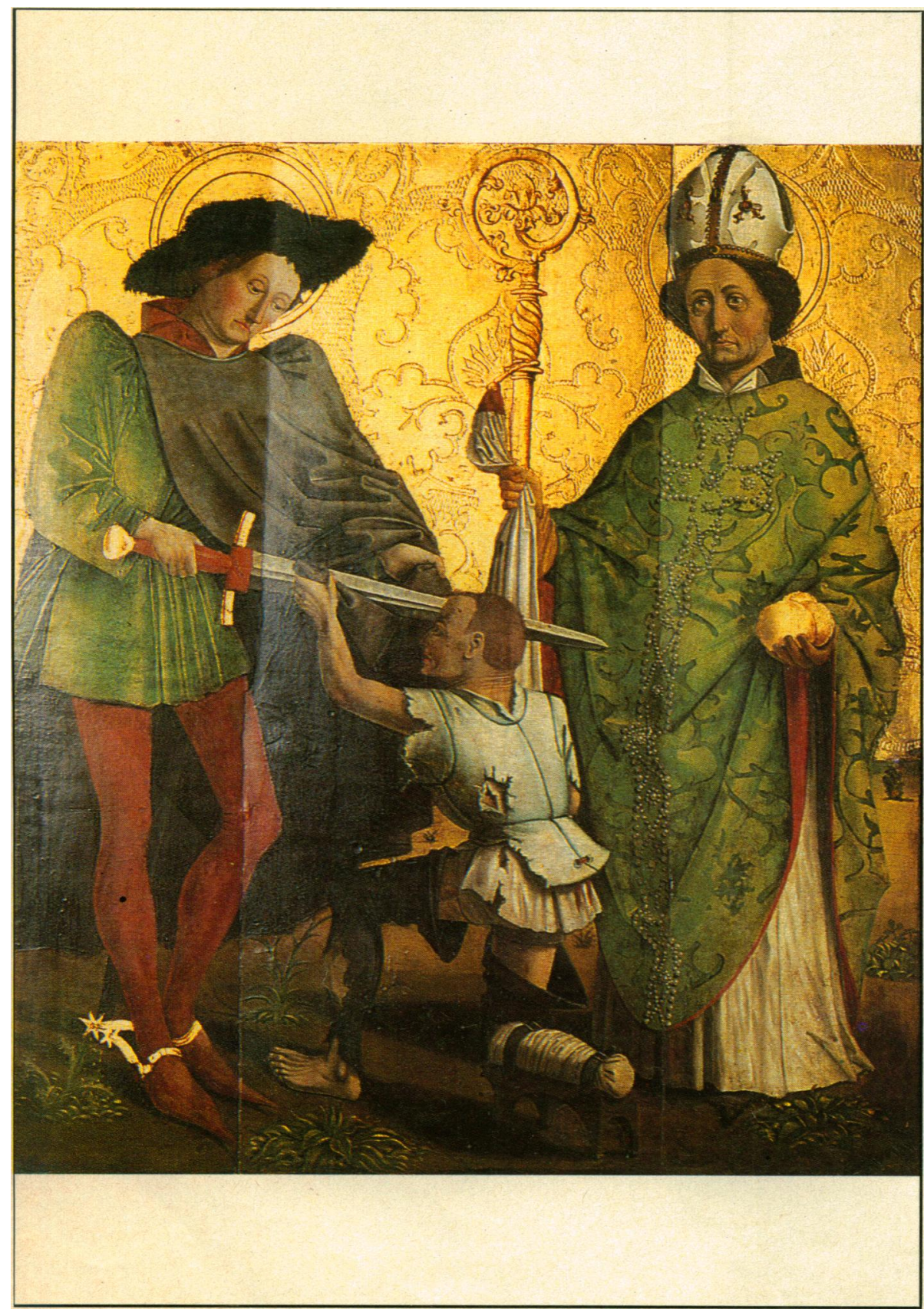

FIG $1-$ St Martin, St Nicholas and the beggar, by the Master of the Uttenheim Altarpiece (fifteenth century). (By permission of the Art Gallery of South Australia.) fourth century BC is probably using a similar contraption. ${ }^{2}$

Three works in the Art Gallery of South Australia illustrate the use of bent knee prostheses. A fifteenth century painting by the Master of the Uttenheim Altarpiece (fig 1) features an amputee beggar wearing a neatly crafted platform support, which is attached to his bandaged leg with two leather straps fastened with buckles. The orderliness

of the bandage and the prosthesis contrasts conspicuously with his beggar's rags.

The artist of St Martin with his horse in a ship (circa 1550) (fig 2) shows several severely deformed figures, many of whom have orthopaedic interest; included among them in the lower right corner of the picture is a man wearing a pair of platform prostheses similar to that described above. He seems to have had at least one leg amputated at the ankle and is using a pair of prostheses to enable him to keep both legs at the same height-the beggar in the previous painting must have had a curious gait. In this case the legs are bandaged to the platforms.

Not all of these older prostheses required the wearer to walk in such an awkward fashion, and in The temptation of St Anthony (fig 3), from the school of Hieronymous Bosch (sixteenth century), a man is shown using a bent knee support that allows him to walk upright with the additional aid of a crutch.

These pictures, as well as illustrating some of the history of walking aids, show several examples of severe flexion and rotational deformities that may result from a lack of rehabilitative physiotherapy. Such contractures are readily prevented by appropriate treatment these days, and the bent knee prosthesis is extremely useful for patients with temporary loss of the use of one leg. Such devices may also be useful permanent aids for victims of poliomyelitis left with one contracted and useless limb and for below knee amputees, for whom preventive physiotherapy and modern socketed prostheses are not readily available: one of us (D D'AW) has used the principle to help such patients in Ethiopia.

Recent enthusiasm for Mr Reid's K9 is certainly justified ${ }^{134}$ : it is a worthy descendant of a long line of walking aids.

\section{References}

1 Reid M. Orthopaedic scooter. Br Med f 1986;292:1121-2. 2 Putti V. Historic artificial limbs. Am J Surg 1929;6:111-8. 3 Weston PM Orthopedic scooter. Br Med 7 1986:292:1460.

Department of Veterans' Affairs, GPO Box 1652 , Adelaide 5001, South Australia

D D'A WEBLING, MB, DTM\&H, director of medical services

Central Development Unit for Prosthetics and Orthotics, Department of Veterans' Affairs, PO Box 211, Kew 3101, Victoria

M FAHRER, MD, FRACS, director 


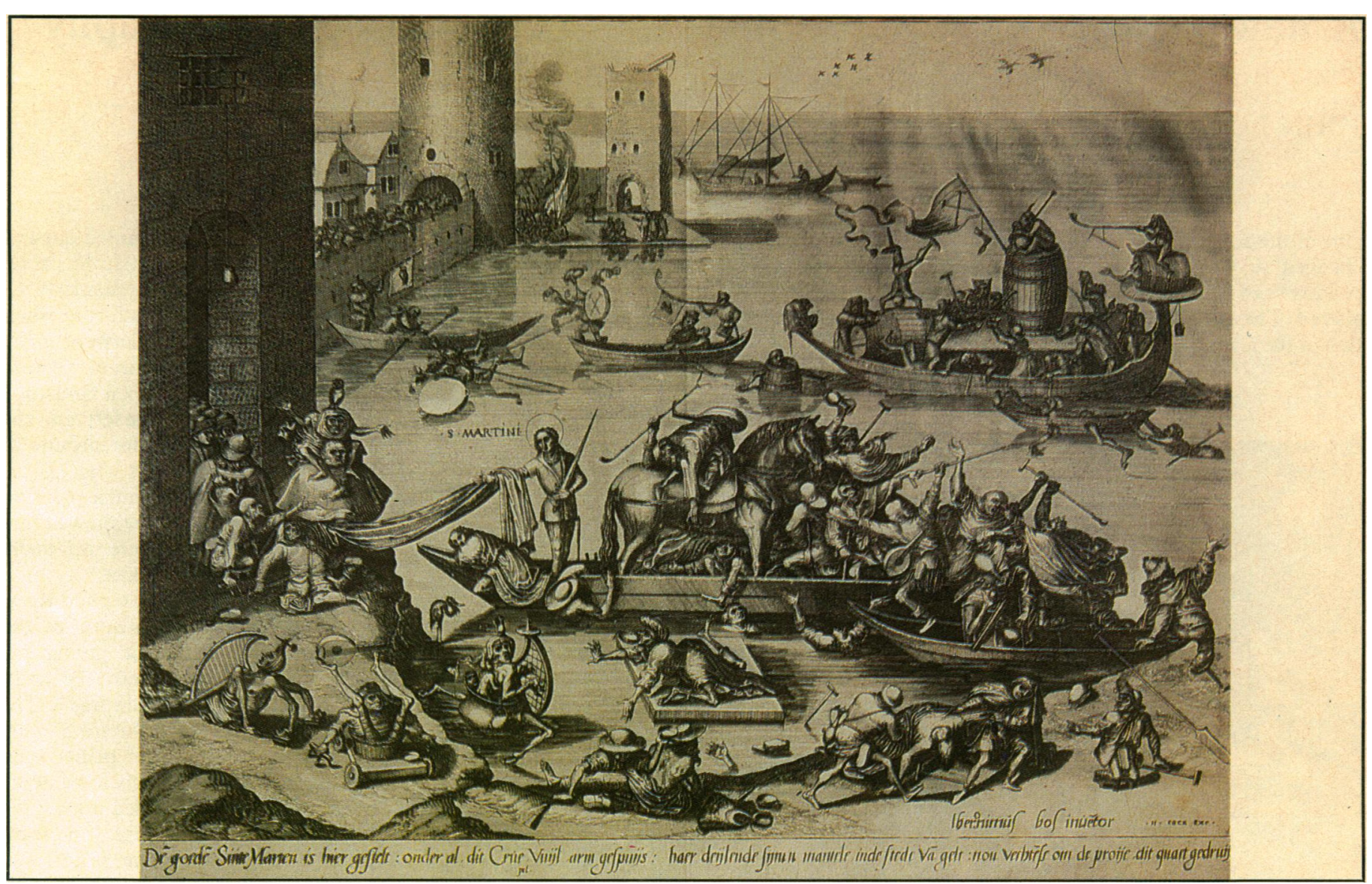

FIG 2-St Martin with his horse in a ship, from the school of Hieronymus Bosch (sixteenth century). (By permission of the Art Gallery of South Australia.)

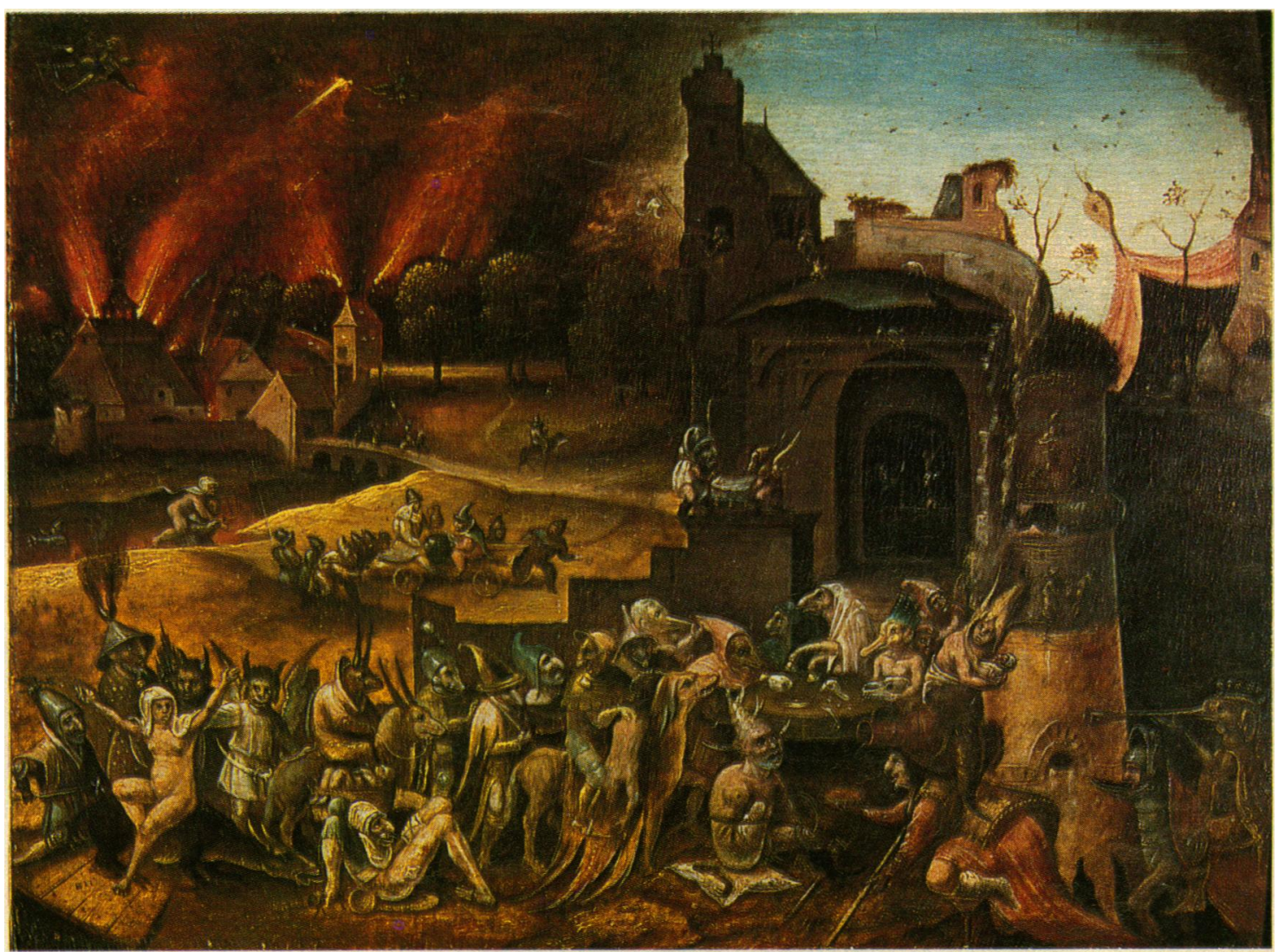

